With end user programs becoming available, "long distance searches" may not be so attractive, but faced with the present economic conditions in higher education, resource sharing in all forms seems worthy of consideration. The ability of the small academic library to offer the latest information techniques will depend heavily upon creative and imaginative library programs.

\title{
Training online catalog assistants: Creating a friendly interface
}

\author{
By Harvey Sager \\ Instructional Services Librarian \\ Arizona State University
}

\section{The design and implementation of a staff training program for online catalog assistants at ASU.}

\footnotetext{
$\mathbf{T}$ he use of library assistants to provide ondemand assistance to users of Online Public Access Catalogs (OPACs) has been a successful component of OPAC instructional programs at several academic libraries. This article suggests the benefits that can accrue to the individual participants as well as to the library as a whole when such a program is implemented, and describes the staff training program developed at Arizona State University Libraries to prepare staff volunteers to serve as PAC assistants.

More than a year prior to "going public" with our Libraries' ALIS III online catalog, indeed while the online catalog was still in its design stage, a committee of seven librarians representing a cross section from public services and the branch libraries was appointed by the assistant university librarian for automated systems and charged with the task of designing and implementing an orientation and training program in the use of our new online catalog for our library staff and public. Specifically, the committee was charged with finding a solution to the anticipated instructional "crunch" which, it was feared, would inevitably affect the
}

public service staff in the main and science library reference service areas where the online catalog terminals would be located.

In other words, we had to find a way to meet the anticipated need for online catalog instruction in our reference areas without sacrificing the quantity and quality of existing reference and informational services already being provided to our students and faculty - and we had to do it with existing library staff.

The committee agreed that one component of such a program should include a corps of trained volunteers recruited from the existing library staff to be stationed in the main and science library reference areas during our busiest hours to provide patron assistance in the use of the new online catalog, thereby freeing the reference librarians and information desk personnel to carry on business as usual. Such a program, we speculated, would provide benefits to the trainee participants as well as to the library. Specifically, it would provide opportunities for motivated and outgoing staff (and every library has such employees) to:

1) receive some special recognition and visibility 
by working directly with the public in an instructional capacity;

2) to exercise, discover, or acquire new public contact skills;

3) to expand their knowledge and understanding of library operations outside their own department (all online assistants were recruited from nonreference department staff);

4) to learn new library skills and add variety to their jobs.

Most importantly, perhaps, this program would give staff members an opportunity to be active participants rather than mere spectators in an exciting period of the Libraries' evolution.

Beyond merely relieving reference librarians and information desk staff from an anticipated tidal wave of online catalog questions, such a program, it was hoped, would bring equal benefits to the library as a whole. First, the library would benefit from improved interdepartmental communication and cooperation which could result from a library-wide staff development program. Such a program also had the potential to make less distinct the us versus them divisions between librarians and classified staff which are part of most library environments. This would be a result of the program design itself, which treated librarians and online catalog assistants equally in terms of the training each group received. Lastly, and quite practically, these staff "volunteers" would serve as the pilot group; the first to go through the complete catalog training program. They would help us test and evaluate the training program which would then be administered to the rest of the participating library staff.

\section{Recruiting staff}

Library staff were continuously kept abreast of developments regarding the implementation of the online catalog through the Libraries' in-house newsletter in a regular "Automation Update" column written by the assistant university librarian for automated systems. Our first call for Public Access Catalog (PAC) volunteers to assist users was sent via this newsletter which reaches all library staff. The committee was seeking eight courageous staff volunteers who, with the approval of their supervisors, would be willing to be guinea pigs for our committee to test the effectiveness of the training program we had developed.

The call for volunteers invited participants to critique the training and the trainers, and held the promise of an opportunity to join the ranks of the first PAC-ettes, as they were dubbed, who it was hoped would form the core of a future expanded group of online-catalog assistants. A follow-up letter was sent to all department heads asking them to personally drum up a little staff support and interest in the program and possibly seek out employees whom they felt would make interested and capable PAC-ettes. Our call for volunteers provided the necessary quorum of eight, plus two "alternates."

\section{The training program}

During this time our committee had not been idle. We had written a 100-plus page Users Manual for the online catalog; had developed and produced prototypes of the basic point-of-use instructional materials we could provide to the public; had evaluated and made recommendations on changes and enhancements to various versions of the online catalog released by the vendor; had written online "HELP" screens; had drafted a script to use in the training program; had developed a series of catalog "exercises" to be used in training; and lastly, we had decided that our committee would do the training. These constituted the basic elements of our training program.

The program was conceived as two two-hour intensive training sessions offered in the main library's instructional classroom where four PAC terminals were installed.

Prior to the first training session, our first eight trainees were sent a packet of training materials which included a printed copy of the online HELP screens the committee had recently written and a copy of a bookmark designed by the committee containing the basic system commands and functions. Each was also encouraged to review the hotoff-the-press ALIS Users Manual, copies of which were made available.

The first two-hour session was devoted to an overview and description of the online catalog, an introduction to the keyboard explaining functions of specific keys (backspace, tab, char/insert, etc.) and a hands-on session in which trainees worked through a series of practice searches designed to demonstrate the various capabilities, strengths and weaknesses of the system as it then existed. Trainees were then given a take-home assignment of slightly greater difficulty, which they were asked to complete and bring to the second training session to be held several days later.

The second two-hour training session was devoted to a review of the subject matter treated in the first session, followed by a step-by-step review of the take-home assignment. We also identified difficulties encountered by the trainees and discussed alternate search strategies for answering the questions. Then, a brief amount of time was devoted to "dealing with the public" and potential "problem" patrons, at that time perceived mainly as computerphobes or frustrated and angry antitechnology types (these two products of our imagination, or of our own misgivings, never really did emerge).

Lastly, trainees were given two brief evaluation instruments to complete. The first was a combination of "find what's wrong," fill-in-the-blank, and short answer type questions designed to assess the trainee's general understanding of the system; the second, a brief terminal exercise to assess their mastery of basic search skills and strategies. Each "quiz" took 10 minutes. Trainee feedback during the first, and especially the second sessions, as well 
as data gathered from the evaluation instruments was useful in identifying areas where trainers needed to place more emphasis, and helped us identify system features with which trainees needed more practice and instruction. Knowledge gained from these first training sessions and from the trainees' frank evaluation of the program resulted in some modification of the training script and in a more structured approach in the review segment of the second session.

This training program for our Online Catalog Assistants served as the model for training the remaining library staff, including librarians, in the use of our Libraries' new online catalog.

Library members were signed up for these training sessions (14 groups in all) in priority order, with librarians and staff who would be interpreting the online catalog for the public being trained first, and those staff who wanted training but would not be working with the catalog or the public in the course of their regular duties being trained last. In all, over eighty librarians and classified staff participated in the general training program.

The PAC-ettes later became the "ALIS Assistants" (a name change more in keeping with the terminology in our written instructional and promotional materials) and their numbers briefly swelled to over twenty volunteers after a second round of recruiting. Because attrition and scheduling conflicts have since reduced their ranks somewhat, ALIS assistants are still routinely recruited through our libraries' orientation program for new staff.

From personal observation of their work and feedback from the ALIS assistants themselves, it is my opinion that the program has been a valuable asset for the libraries, and has proven personally rewarding to all those who have participatedtrainees and trainers alike.

\section{Books for College Libraries}

In the fall of 1984 Choice responded to a request for a proposal (RFP) issued by the Association of College and Research Libraries (ACRL) to compile a new edition of Books for College Libraries (BCL). The RFP was the result of an ad hoc committee established by ACRL to determine whether another revision of this standard work was needed in the academic library community.

The first edition of BCL was published in 1967 by the American Library Association. The work contained 53,410 titles edited by Melvin J. Voight, university librarian, and Joseph H. Treyz, head of the New Campus Program of the University of California, San Diego. This edition represented the core title list of the New Campuses Program for the University of California, as revised by Choice editors and reviewers. The founding of Choice, whose first issue appeared in March 1964, was seen as a complement to this core list although no official tiein was developed other than the 1963 cut-off date for titles in the 1967 edition.

ALA published the second edition of BCL in 1975 with funding from the Council on Library Resources to produce a library catalog of 40,000 volumes for college libraries $(38,651$ titles are in the 1975 edition). The 1967 edition and Choice reviews through 1972 served as the main basis for the 1975 edition. Choice reviewers and other librarians and subject experts made the selections. The new machine-readable cataloging program (MARC) developed at the Library of Congress was seen as a source of bibliographic data about selected titles. Only about a third of the titles selected by scholars, librarians, and specialists were found to be available on the MARC file, however, and MARC tagging of other titles was done by the proj- ect's computer contractor

The third edition of BCL, an anticipated 50,000-title collection, is currently being compiled at the Choice offices. The editor of Choice, Pat Sabosik, is overall project manager. Virginia Clark, on leave from her position as assistant editor at Choice, is serving as editor of the new edition. ALA will again be the publisher (co-publishing with ACRL) and an estimated publication date of the six-volume work is set for late 1987.

Strong ties to the Choice operation are again evident in this edition. Choice subject editors are recommending reviewers to be invited to work on the project. These reviewers are developing subject lists for the new edition using pages from the 1975 edition and selected Choice cards from 1972 through 1985. As in the past, they are also invited to recommend other titles. Approximately 500 reviewers of the 3,000 reviewer pool will be used in this first pass selection process. Unique to this edition will be a second pass at review and selection by academic librarians responsible for selection and collection development in the various subjects. An estimated 200 librarians will be used for this stage of the process.

The database development for the project has been subcontracted to UTLAS, Inc., a vendor of online bibliographic databases. An estimated 27,000 titles, representing faculty selections, are now in the BCL III in-process database, and the BCL III staff is experiencing a $96 \%$ hit rate of titles requested from the UTLAS master file.

With such complete database backup available through current MARC cataloging and reconversion projects, it will be possible to update BCL on a more frequent basis. The Choice Editorial Board 
and the BCL III Advisory Committee will be studying the updating issue in the next few years and making recommendations to Choice and ACRL for a more current review and revision cycle.

The high degree of involvement of the Choice staff and reviewer pool in the revision of BCL is indicative of their commitment to publish usable, high quality collection development resources for academic libraries.

$C \triangleleft R L$ News readers who would like to volunteer or to recommend colleagues for the librarian review stage of the BCL III project are invited to submit names and a statement of subject interest and qualifications to Virginia Clark, Editor BCL, Choice, 100 Riverview Center, Middletown, CT 06457 .

\section{ACRL candidates, 1987 elections}

\section{Who's who on the Spring ballot.}

he listing for each of the following candidates includes their title, institution, and institutional address.

\section{Vice-President/President-Elect}

Joseph Boissé, University Librarian, University of California, Santa Barbara, CA 93106; Joan Chambers, Director of Libraries, Colorado State University, Fort Collins, CO 80523.

\section{Board of Directors}

Director-at-Large: Charles S. Fineman, Hu manities Bibliographer, Collection Management Office, Northwestern University Library, 1935 Sheridan Road, Evanston, IL 60201-2924; Peter Malanchuk, Chairman, Department of Reference and Bibliography, 116 Library West, University of Florida, Gainesville, FL 32611.

Director-at-Large: Larry Hardesty, Director of Library Services, Eckerd College Library, P.O. Box 12560, St. Petersburg, FL 33733; Norma Yueh, Director of Library Services, Ramapo College of New Jersey, Mahwah, NJ 07430.

\section{Anthropology and Sociology Section (ANSS)}

Vice-Chair/Chair-Elect: Stephen E. MacLeod, Social Sciences Bibliographer, Green Library, Stanford University, Stanford, CA 94305.

Secretary: Deborah A. Kane, Social Science Reference Librarian, Reference Department, Univer- sity Library, University of Nebraska at Omaha, Omaha, NE 68182; Cheryl C. Kugler, Head of Monograph Services, Jean \& Alexander Heard Library, Vanderbilt University, 419 21st Ave. South, Nashville, TN 37205.

Member-at-Large: Jo Kibbee, Anthropology Subject Specialist, 100 Library, University of Illinois, Urbana, IL 61801; Virginia F. Moreland, Computer Search Coordinator, University Libraries, University of Nebraska, Lincoln, NE 68588-0410.

\section{Art Section (ARTS)}

Vice-Chair/Chair-Elect: Charles R. Smith, Humanities Reference Librarian, Sterling C. Evans Library, Texas A\&M University, College Station, TX 77843.

Secretary: Micheline Nilsen, Creative Arts Librarian, Cheever Hall, Montana State University, Bozeman, MT 59717; Stephen Allan Patrick, Head, Documents Department, Sherrod Library, East Tennessee State University, P.O. Box 22450 A, Johnson City, TN 37614-0002.

\section{Asian and African Section (AAS)}

Vice-Chair/Chair-Elect: Basima Q. Bezirgan, 5000 S. Cornell, \#7B, Chicago, IL 60615; Katharine K. Elsasser, Head, Humanities I Section, Subject Cataloging Division, Library of Congress, Washington, DC 20540.

Member-at-Large: Eleanor Murphy Daniel, 